Tropical Journal of Pharmaceutical Research March 2017; 16 (3): 543-552

ISSN: $1596-5996$ (print); 1596-9827 (electronic)

(C) Pharmacotherapy Group, Faculty of Pharmacy, University of Benin, Benin City, 300001 Nigeria.

All rights reserved.

Available online at http://www.tjpr.org

Original Research Article

http://dx.doi.org/10.4314/tjpr.v16i3.7

\title{
Anti-diabetic activity-guided screening of aqueous-ethanol Moringa oleifera extracts and fractions: Identification of marker compounds
}

\author{
Hafiz Muhammad Irfan ${ }^{1,2 \star}$, Mohd Zaini Asmawi ${ }^{1}$, Nurzalina Abdul Karim Khan ${ }^{1}$, \\ Amirin Sadikun ${ }^{1}$ and Mohd Nizam Mordi ${ }^{3}$ \\ ${ }^{1}$ School of Pharmaceutical Sciences, Universiti Sains Malaysia, Pulau Pinang, Malaysia, ${ }^{2}$ Faculty of Pharmacy, Department of \\ Pharmacology, University of Sargodha, Sargodha, Pakistan, ${ }^{3}$ Centre for Drug Research, Universiti Sains Malaysia, Pulau \\ Pinang, Malaysia
}

*For correspondence: Email: irfan_pharmacist06@yahoo.com; Tel: +60104300950

\begin{abstract}
Purpose: To explore the anti-diabetic effects of Moringa oleifera extracts and fractions, and to identify their active/marker compounds.

Methods: Five different aqueous ethanol extracts $(95,75,50,25 \% \mathrm{v} / \mathrm{v}$ and $100 \%$ water) of Moringa oleifera were given orally to normal rats to assess their hypoglycemic activities and effect on intraperitoneal glucose tolerance test (IPGTT) data. Rats with streptozotocin-induced diabetes were used to assess acute and sub-chronic anti-hyperglycemic activities. The most active extract was further subjected to liquid-liquid fractionation into hexane, chloroform, ethyl acetate, butanol, and water; these fractions were screened for anti-diabetic activities. The most active extract, and fractions thereof, were then subjected to qualitative and quantitative phytochemical analysis. Standardization was achieved via thin layer chromatography (TLC) and high-performance liquid chromatography (HPLC), and used to identify marker compounds.

Results: Of all the extracts and fractions, $95 \%(\mathrm{v} / \mathrm{v})$ ethanol extract (at 1,000 $\mathrm{mg} / \mathrm{kg})$ and the butanol fraction thereof (at $500 \mathrm{mg} / \mathrm{kg}$ ) were the most active, reducing blood glucose concentration after onetime (acute) administration to diabetic rats $(p<0.01)$. No significant hypoglycemic activity was apparent, and the materials had no effect on IPGTT performance by normal rats. TLC and HPLC identified quercetin 3- $\beta$-D-glucoside, kaempferol-3-O-glucoside, and cryptochlorogenic acid.

Conclusion: An M. oleifera leaf extract exhibited anti-hyperglycaemic activity in diabetic rats only. This effect was likely attributable to cryptochlorogenic acid, quercetin 3- $\beta$-D-glucoside, and kaempferol 3-Oglucoside.
\end{abstract}

Keywords: Anti-diabetic, Moringa oleifera, Cryptochlorogenic acid, Quercetin 3- $\beta$-D-glucoside, Kaempferol 3-O-glucoside, Streptozotocin

Tropical Journal of Pharmaceutical Research is indexed by Science Citation Index (SciSearch), Scopus, International Pharmaceutical Abstract, Chemical Abstracts, Embase, Index Copernicus, EBSCO, African Index Medicus, JournalSeek, Journal Citation Reports/Science Edition, Directory of Open Access Journals (DOAJ), African Journal Online, Bioline International, Open-J-Gate and Pharmacy Abstracts

\section{INTRODUCTION}

Glucose homeostasis is the balance between glucose production and utilisation by peripheral tissues. Insulin promotes glucose uptake by cells [1]. An insulin deficiency combined with insulin resistance is responsible for diabetes mellitus [2]. The World Health Organization has observed that diabetes has become a major problem, and the number of cases is expected to rise through the year 2035 [3]. The prevalence of diabetes is 
increasing among Malaysians, reaching $23.8 \%$ in recent years [4].

Natural products and their derivatives constitute ca. $50 \%$ of all anti-diabetics. The rate is higher when related synthetic materials are considered [5], but these materials are costly [6]. Generally, various extracts of natural materials are subjected to primary screening and the best extract is selected [7].

Marker compounds therein are identified using standard techniques [8]. High-performance liquid chromatography (HPLC) and thin layer chromatography (TLC) are valuable chromatographic techniques [9] employed to identify molecules responsible for therapeutic activities [10].

Recently, advances in the isolation and identification of active compounds in medicinal plants have featured fractionation-guided targeting.

Therefore, we identified active anti-diabetic compounds in extracts and fractions of Moringa oleifera. Our findings will aid future drug discovery/extraction from natural sources.

\section{EXPERIMENTAL}

\section{Apparatus, chemicals, and drugs}

A rotary evaporator (Buchi Labotechnik, $\mathrm{CH}$ 9230 Flawil Switzerland), a WinCATS Planar Chromatography Manager (Merck, Germany), streptozotocin (Sigma Aldrich Chemical Co, USA), acetonitrile and formic acid (Merck, Germany), quercetin 3- $\beta$-D-glucoside (Sigma Aldrich, USA), kaempferol 3-O-glucoside (48010-4, Extrasynthese, Genay Cedex), cryptochlorogenic acid (Wuhan ChemFaces Biochemical Co. Ltd), glibenclamide $5 \mathrm{mg}$ (Daonil) and metformine (500 mg; Glucophage; Merck, Germany) were used in this study.

\section{Authentication of the plant and preparation of extracts}

Plant material was purchased from Harbagus Sdn. Bhd., Pulau Pinang, Malaysia, and was authenticated by Dr Rahmad Zakaria. A voucher specimen has been placed in the herbarium of School of botany, Universiti Sains Malaysia (no. 11626). M. oleifera leaves were dried in the shade, ground to a powder, and extracted with $95,75,50$, and $25 \%(\mathrm{v} / \mathrm{v})$ ethanol and $100 \%$ water via maceration (Table 1). All extracts were concentrated under reduced pressure in a rotary evaporator and dried in an oven at $45^{\circ} \mathrm{C}$.

\section{Experimental animals}

Healthy male adult Sprague Dawley (SD) rats aged 8 - 9 weeks $(230 \pm 30 \mathrm{~g}$ body weight) were used in the experimental studies. The animals were obtained from the Animal Research and Service Centre (ARASC), Universiti Sains Malaysia and allowed to adapt for seven days in the transit room of the School of Pharmaceutical Sciences at a temperature of $25 \pm 3{ }^{\circ} \mathrm{C}$ under a 12/12-h dark/light cycle. The rats had ad libitum access to rat pellets and water. The Animal Ethics Committee of Universiti Sains Malaysia approved the work (approval no. AEA/2015/612) and was performed in compliance with international guidelines $(\mathrm{NIH})$ for the care and use of animals [11].

\section{Blood glucose measurement}

Blood samples (single drops) were collected by nicking the tail vein, and blood glucose (BG) levels were determined using a glucometer (Roche, ACCU-CHEK Performa no. 55404068967).

\section{Anti-diabetic studies}

\section{Hypoglycaemia in normoglycaemic rats}

Forty-two male SD rats were used to measure hypoglycaemic activity. The negative control (NC) and positive control (PC) groups were given distilled water $(10 \mathrm{~mL} / \mathrm{kg})$ and water containing glibenclamide (10 mg/kg), respectively. The treated groups were given 95, 75, 50 and $25 \%$ (v/v) ethanol and $100 \%$ water extracts $(1,000$ $\mathrm{mg} / \mathrm{kg}$ orally). After $14 \mathrm{~h}$ overnight fasting, fasting blood glucose (FBG) levels were determined; the treatments were then applied, and glucose levels were measured 1, 3, 5 and $7 \mathrm{~h}$ later.

\section{Intraperitoneal glucose tolerance test in normoglycaemic rats}

Normal rats were divided randomly into eight groups. One hour after oral administration of all treatments, the rats were injected intraperitoneally with a glucose load $(500 \mathrm{mg} / \mathrm{kg}$ body weight). BG levels were measured at 0,15 , $30,45,60,90$, and 120 min thereafter.

\section{Anti-hyperglycaemic activity in streptozo-} tocin-treated rats: single-dose study

Diabetes was induced by intraperitoneal injection of streptozotocin ( $45 \mathrm{mg} / \mathrm{kg}$ body weight) after overnight fasting. Glucose was added to the drinking water (to $5 \%, \mathrm{w} / \mathrm{v}$ ) for $12 \mathrm{~h}$ to reduce mortality caused by hypoglycaemia. BG levels 
were measured $72 \mathrm{~h}$ later. Rats with FBG concentrations $>15 \mathrm{mmol} / \mathrm{L}$ were considered to be diabetic and were used in further studies.

To measure anti-hyperglycaemic activity, rats were divided into seven groups. The experimental protocol was as described above, except that the $\mathrm{PC}$ group received metformin $(500 \mathrm{mg} / \mathrm{kg})$.

\section{Anti-hyperglycaemic activity in streptozo- tocin-treated rats: multiple-dose study}

The groups formed were the same as those created for the single-dose study described above. Diabetic rats were treated with $M$. oleifera aqueous ethanol extracts $(1,000 \mathrm{mg} / \mathrm{kg})$ once daily for 14 days. BG levels were determined on day- 0,7 and 14 after overnight fasting.

\section{Fractionation (Liquid-liquid extraction)}

The most active extract (the $95 \%$ [v/v] ethanol) of $M$. oleifera was subjected to further fractionation. The extract was first partitioned with distilled water, and then (serially) with hexane, chloroform, ethyl acetate, and butanol, in a separating funnel. All five fractions (hexane, chloroform, ethyl acetate, butanol, and water) were concentrated separately under reduced pressure in rotary evaporator and dried in an oven at $45^{\circ} \mathrm{C}$.

\section{Anti-hyperglycaemic screening of $M$. oleifera fractions in the rat streptozotocin model}

Seven groups (six rats per group) were used. All groups underwent treatment with fractions (500 $\mathrm{mg} / \mathrm{kg}$ ) suspended in $10 \%(\mathrm{v} / \mathrm{v})$ Tween 80 . FBG levels were determined after administration of various fractions and a standard drug at 1, 3, 5, and $7 \mathrm{~h}$

\section{Phytochemical screening of extracts and fractions}

For qualitative phytochemical screening, samples (extracts and fractions) were dissolved in dimethyl sulfoxide. Tannins, phenols, saponins, flavonoids, alkaloids, terpenoids, and glycosides were assayed using standard tests [12,13].

\section{Thin layer chromatography}

Qualitative screening of active compounds was performed on $20 \times 20-\mathrm{cm}$ silica gel TLC plates (Merck). The samples (the $95 \%$ ethanol extract and the butanol fraction) were dissolved to 5 $\mathrm{mg} / \mathrm{mL}$ and the standards (cryptochlorogenic acid, kaempferol-3-O-glucoside, and quercetin 3$\beta$-D-glucoside) were dissolved to $1 \mathrm{mg} / \mathrm{mL}$. The TLC plates were developed in a TLC chamber $(10 \times 10 \mathrm{~cm})$; the mobile phase was ethyl acetate: methanol: Acetic acid: water (110: 13.5: 8: 8 by volume). The plates were sprayed with the natural product (NP) reagent and viewed under ultraviolet light at 254 and $366 \mathrm{~nm}$ with the aid of a winCATS Planar Chromatography Manager. Rf values were calculated using equation 1 :

$\mathrm{Rf}=$ distance travelled by compound / distance travelled by solvent front

\section{HPLC development and validation}

A $95 \%(v / v)$ ethanol extract, the butanol fraction thereof $(1,000 \mathrm{ppm})$, and standard compound (2,000 ppm) stock solutions were prepared in methanol, filtered through syringe filter $(0.45-\mu \mathrm{m}$ pore size), and analysed on an 1100/1200 HPLC plateform (Agilent Technologies, USA) fitted with a column thermostat, a quaternary pump, a diode array detector, and an agilent 1200 autosampler (SL 1). We used a Hypersil Gold C4 column with a particle size of $5.0 \mu \mathrm{m}$ and dimensions of 250.0 $\times 4.6 \mathrm{~mm}$ (Thermo-Scientific, USA). The solvent systems were $0.1 \%(\mathrm{v} / \mathrm{v})$ formic acid (B) and acetonitrile $(\mathrm{C})$, and elution employed the following gradient: 0 - $5 \mathrm{~min}, \mathrm{~B}(97 \%)$ and C (3 $\%) ; 5$ - $14.5 \mathrm{~min}, \mathrm{~B}(80 \%)$ and C (20\%); 14.5 $16.5 \mathrm{~min}, \mathrm{~B}(97 \%)$ and C (3\%). The injection volume was $20 \mu \mathrm{L}$, the column flow rate was 1.2 $\mathrm{mL} / \mathrm{min}$, and the run time was $18 \mathrm{~min}$. All chromatographic signals were detected at 344 $\mathrm{nm}$.

\section{Quantification of identified compounds}

To quantify cryptochlorogenic acid, quercetin 3$\beta$-D-glucoside, and kaempferol-3-O-glucoside in the active $95 \%(\mathrm{v} / \mathrm{v})$ ethanol extract and the butanol fraction thereof, the peak heights of samples were compared with those of standards.

\section{Evaluation of linearity, accuracy and precision}

Linearity was checked by evaluating the peak heights (in mAU) of standards (12.5 - 200 $\mu \mathrm{g} / \mathrm{mL})$. Accuracy was evaluated by checking agreement between the amounts applied and the amounts measured by HPLC. We also evaluated the repeatability (precision) of the method. We injected three sets of standard mixtures three times daily over 3 consecutive days and measured intra-day and inter-day accuracy and precision. 


\section{Statistical analysis}

The results are presented as mean \pm standard deviations and were analyzed by one-way analysis of variance with the aid of IBM SPSS software, followed by Dunnett's post hoc test. Differences between means were considered to be statistically significant at $p<0.05,<0.01$, or $<$ 0.001 . For graphical presentation, GraphPad Prism (version 6.0) software was used.

\section{RESULTS}

\section{Effect of extracts of Moringa oleifera in normal rats}

BG concentrations rose after administration of all extracts $(95,75,50,25 \%[\mathrm{v} / \mathrm{v}]$ ethanol and water) for up to $3 \mathrm{~h}$ (compared with FBG levels), but declined over the next $4 \mathrm{~h}$ (Table 2). No significant reduction in glucose concentration was observed, except in the glibenclamide group (31.81\%).

\section{Effect of different extracts on IPGTT in normoglycemic rat}

Glibenclamide greatly lowered the BG concentration (by $35.52 \%) 15$ min after glucose loading, compared with the NC. Similarly, the treated groups exhibited some improvements in glucose tolerance (GT) at $15 \mathrm{~min}$, but these differences were not significant. The 95 and 50 $\%(v / v)$ ethanol extracts afforded only $12.41 \%$ improvement in GT. GTs were 5.4, 10.64, and $11.73 \%$ after administration of 75 and $25 \%(\mathrm{v} / \mathrm{v})$ ethanol and aqueous extracts, respectively (Table 3).

\section{Effects of multiple-dose M. oleifera extracts in diabetic rats}

The ethanol $(95,75,50$, and $25 \%[\mathrm{v} / \mathrm{v}])$ and aqueous extracts, metformin, significantly reduced the BG levels on days 7 and 14 after overnight fasting $(p<0.001$; Figure 1$)$. On day 7 , the 50 and $25 \%(\mathrm{v} / \mathrm{v})$ extracts reduced the BG concentration by 55.35 and $54.57 \%$, whereas the reduction afforded by the $95 \%(\mathrm{v} / \mathrm{v})$ extract was $64.07 \%$ compared with the control. Likewise, the aqueous extract afforded a 60.06 $\%$ reduction in $B G$ level compared with the initial value $(19.28 \pm 0.36 \mathrm{mmol} / \mathrm{L})$.

\section{Effects of single-dose $M$. oleifera extract in diabetic rats}

Metformin afforded $42.87 \%$ reduction in hyperglycaemia, compared with the NC, $7 \mathrm{~h}$ after administration (Table 4). The 95 and $75 \%$ (v/v) ethanol extracts lowered the BG level by 30.28 and $18.05 \%$, respectively. The 50 and $25 \%(\mathrm{v} / \mathrm{v})$ ethanol extracts did not markedly reduce the BG level, whereas the aqueous extract lowered the BG level significantly to only $1 \mathrm{~h}$ after administration $(p<0.05)$.

Table 1: $M$. oleifera aqueous-ethanol extracts

\begin{tabular}{|c|c|c|c|c|}
\hline $\begin{array}{l}\text { Extracts } \\
\text { (V/V) } \\
\text { Ethanol (95\%): water }(\mathrm{mL})\end{array}$ & $\begin{array}{l}\text { Weight of } \\
\text { dried leaves } \\
\text { powder } \\
\text { (g) }\end{array}$ & $\begin{array}{l}\text { Weight of } \\
\text { extract } \\
\text { (g) }\end{array}$ & Physical appearance & Yield (\%) \\
\hline $95 \%(1000: 0)$ & 800 & 184.45 & $\begin{array}{l}\text { Black-greenish and sticky } \\
\text { and oily }\end{array}$ & 23 \\
\hline $75 \%$ (789: 211) & 800 & 214.96 & Dark brown and sticky & 26.87 \\
\hline $50 \%(526: 474)$ & 800 & 192.76 & Dark brown and sticky & 24.01 \\
\hline 25\% (263: 737) & 800 & 253.81 & Dark brown and sticky & 31.72 \\
\hline Water $(0: 1000)$ & 800 & 217.75 & Dark brown & 27.22 \\
\hline
\end{tabular}

Table 2: Effect of $M$. oleifera extracts in normal rats $(n=6)$

\begin{tabular}{lcccccc}
\hline \multirow{2}{*}{ Sample/extract } & \multicolumn{2}{c}{ Dose/kg } & \multicolumn{4}{c}{ Blood glucose levels after treatment (mmol/L) } \\
\cline { 2 - 7 } & & $\mathbf{0}$ (FBG) & $\mathbf{1}$ & $\mathbf{3}$ & $\mathbf{5}$ & $\mathbf{7}$ \\
\hline $\mathrm{NC}$ & $10 \mathrm{~mL}$ & $5.1 \pm 0.46$ & $4.98 \pm 0.60$ & $5.01 \pm 0.68$ & $5.06 \pm 0.44$ & $5.13 \pm 0.58$ \\
$\mathrm{G}$ & $10 \mathrm{mg}$ & $4.96 \pm 0.33$ & $3.81 \pm 0.94^{\mathrm{a}}$ & $3.75 \pm 0.77^{\mathrm{b}}$ & $3.45 \pm 0.19^{\mathrm{c}}$ & $4.1 \pm 0.43^{\mathrm{a}}$ \\
$\mathrm{E} 95 \%$ & $1000 \mathrm{mg}$ & $4.95 \pm 0.48$ & $5.38 \pm 0.61$ & $5.67 \pm 0.44$ & $5.22 \pm 0.44$ & $5.11 \pm 0.65$ \\
$\mathrm{E} 75 \%$ & $1000 \mathrm{mg}$ & $5.15 \pm 0.48$ & $5.52 \pm 0.52$ & $5.62 \pm 0.53$ & $5.28 \pm 0.55$ & $4.75 \pm 0.74$ \\
$\mathrm{E} 50 \%$ & $1000 \mathrm{mg}$ & $5.15 \pm 0.50$ & $5.33 \pm 0.36$ & $5.43 \pm 0.43$ & $5.15 \pm 0.23$ & $5.01 \pm 0.51$ \\
$\mathrm{E} 25 \%$ & $1000 \mathrm{mg}$ & $4.88 \pm 0.44$ & $5.4 \pm 0.76$ & $5.83 \pm 0.66$ & $4.95 \pm 0.82$ & $5.07 \pm 0.48$ \\
$\mathrm{AE}$ & $1000 \mathrm{mg}$ & $5.13 \pm 0.54$ & $5.97 \pm 0.30$ & $5.83 \pm 0.32$ & $5.4 \pm 0.52$ & $5.06 \pm 0.83$
\end{tabular}

$F B G=$ fasting blood glucose, $N C=$ negative control, $G=$ glibenclamide, $E=$ ethanol, $A E=$ aqueous extract, ${ }^{a} p<0.05,{ }^{b}$ $p<0.01,{ }^{c} p<0.001$, treated groups were compared with $N C$ 
Table 3: Effect of $M$. oleifera extracts on IPGTT in normoglycaemic rats $(n=6)$

\begin{tabular}{|c|c|c|c|c|c|c|c|c|}
\hline Treatments & $\begin{array}{c}\text { Dose/kg } \\
\text { body } \\
\text { weight }\end{array}$ & FBG & & Blood gluc & ose levels a & er treatme & $(\mathrm{mmol} / \mathrm{L}))$ & \\
\hline & & $0 \min$ & $15 \mathrm{~min}$ & $30 \mathrm{~min}$ & $45 \mathrm{~min}$ & $60 \mathrm{~min}$ & $90 \mathrm{~min}$ & $120 \mathrm{~min}$ \\
\hline $\mathrm{NC}$ & $10 \mathrm{~mL}$ & $5.22 \pm 0.19$ & $7.33 \pm 0.92$ & $6.38 \pm 0.50$ & $5.38 \pm 0.35$ & $5.12 \pm 0.20$ & $4.97 \pm 0.19$ & $4.77 \pm 0.29$ \\
\hline G & $10 \mathrm{mg}$ & $5.47 \pm 0.31$ & $4.58 \pm 1.13^{\mathrm{C}}$ & $3.75 \pm 0.66^{c}$ & $3.57 \pm 0.70^{c}$ & $3.3 \pm 0.47^{c}$ & $2.88 \pm 0.34^{\mathrm{C}}$ & $2.68 \pm 0.29^{c}$ \\
\hline M & $500 \mathrm{mg}$ & $5.5 \pm 0.54$ & $6.53 \pm 0.53$ & $5.7 \pm 0.30$ & $5.33 \pm 0.33$ & $5.17 \pm 0.30$ & $4.92 \pm 0.40$ & $4.67 \pm 0.53$ \\
\hline E 95\% & $1000 \mathrm{mg}$ & $5.25 \pm 0.45$ & $6.42 \pm 0.60$ & $5.77 \pm 0.30$ & $5.63 \pm 0.36$ & $5.48 \pm 0.34$ & $5.25 \pm 0.38$ & $5.1 \pm 0.39$ \\
\hline E 75\% & $1000 \mathrm{mg}$ & $5.2 \pm 0.49$ & $6.93 \pm 0.90$ & $6.18 \pm 0.49$ & $5.78 \pm 0.64$ & $5.45 \pm 0.37$ & $5.05 \pm 0.24$ & $4.87 \pm 0.32$ \\
\hline E 50\% & $1000 \mathrm{mg}$ & $5.47 \pm 0.38$ & $6.42 \pm 0.86$ & $5.82 \pm 0.43$ & $5.22 \pm 0.34$ & $5.08 \pm 0.31$ & $4.98 \pm 0.31$ & $4.88 \pm 0.55$ \\
\hline E 25\% & $1000 \mathrm{mg}$ & $5.33 \pm 0.50$ & $6.55 \pm 1.08$ & $6.07 \pm 0.63$ & $5.32 \pm 0.31$ & $5.38 \pm 0.48$ & $4.93 \pm 0.12$ & $4.73 \pm 0.27$ \\
\hline$A E$ & $1000 \mathrm{mg}$ & $5.23 \pm 0.28$ & $6.47 \pm 0.69$ & $5.67 \pm 0.27$ & $5.42 \pm 0.35$ & $5.25 \pm 0.34$ & $4.93 \pm 0.12$ & $4.85 \pm 0.29$ \\
\hline
\end{tabular}

$\mathrm{NC}=$ negative control, $\mathrm{G}=$ glibenclamide, $\mathrm{M}=$ Metformine, $\mathrm{E}=$ ethanol, $\mathrm{AE}=$ aqueous extract, $\mathrm{FBG}=$ fasting blood glucose, Statistically compared with NC, ${ }^{a} p<0.05,{ }^{b} p<0.01,{ }^{c} p<0.001$

Table 4: Effects of single dose $M$. oleifera extracts in diabetic rats $(n=6)$

\begin{tabular}{|c|c|c|c|c|c|c|}
\hline \multirow[t]{2}{*}{ Group } & \multirow{2}{*}{$\begin{array}{c}\text { Dose } \\
\text { (per kg) }\end{array}$} & \multirow{2}{*}{$\begin{array}{c}\text { FBG } \\
\text { Oh }\end{array}$} & \multicolumn{4}{|c|}{ Blood glucose levels after treatment (mmol/L) } \\
\hline & & & $1 \mathrm{~h}$ & $3 h$ & $5 \mathrm{~h}$ & $7 h$ \\
\hline NDC & $10 \mathrm{~mL}$ & $20.35 \pm 1.90$ & $21.58 \pm 1.59$ & $20.25 \pm 1.66$ & $20.22 \pm 0.93$ & $20.48 \pm 1.77$ \\
\hline $\mathrm{M}$ & $500 \mathrm{mg}$ & $20.20 \pm 0.98$ & $18.93 \pm 1.23^{\mathrm{a}}$ & $17.23 \pm 2.06^{\mathrm{b}}$ & $15.45 \pm 1.18^{\mathrm{C}}$ & $11.7 \pm 0.96^{\mathrm{C}}(42.08 \%)$ \\
\hline E $95 \%$ & $1000 \mathrm{mg}$ & $19.85 \pm 2.71$ & $18.58 \pm 2.77^{\mathrm{a}}$ & $17.13 \pm 1.86^{\mathrm{b}}$ & $15.92 \pm 2.44^{c}$ & $13.84 \pm 2.41^{\mathrm{c}}(30.28 \%)$ \\
\hline E 75\% & $1000 \mathrm{mg}$ & $20.28 \pm 1.31$ & $20.27 \pm 0.85$ & $18.40 \pm 0.40$ & $17.07 \pm 0.80^{\mathrm{b}}$ & $16.62 \pm 1.33^{\mathrm{D}}(18.05 \%)$ \\
\hline E $50 \%$ & $1000 \mathrm{mg}$ & $18.50 \pm 0.44$ & $19.30 \pm 0.64$ & $19.10 \pm 1.04$ & $18.47 \pm 0.77$ & $18.68 \pm 0.61$ \\
\hline E 25\% & $1000 \mathrm{mg}$ & $19.52 \pm 1.62$ & $19.20 \pm 0.49$ & $19.07 \pm 0.47$ & $19.55 \pm 1.40$ & $18.83 \pm 1.56(3.53 \%)$ \\
\hline $\mathrm{AE}$ & $1000 \mathrm{mg}$ & $19.28 \pm 0.73$ & $18.63 \pm 2.32^{a}$ & $18.33 \pm 1.87$ & $18.22 \pm 0.89$ & $18.03 \pm 0.57(6.48 \%)$ \\
\hline
\end{tabular}

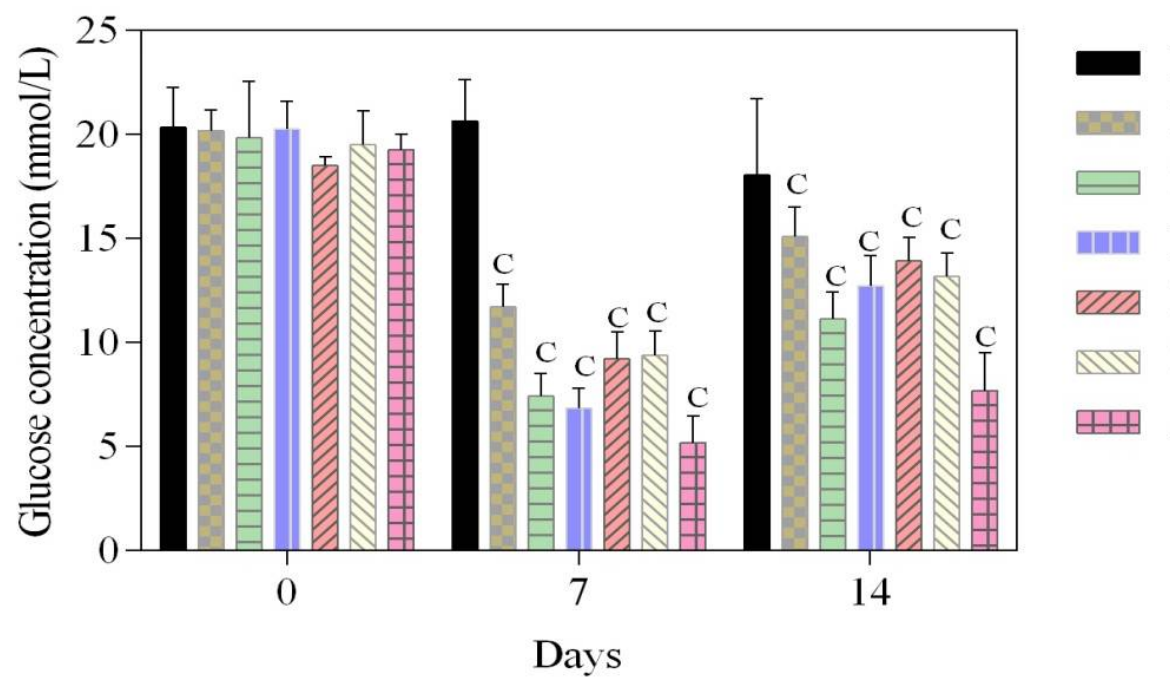
NDC
PDC
E $95 \%$
E $75 \%$
E $50 \%$
E $25 \%$

Aqueous

Figure 1: Effects of multiple-dose $M$. oleifera extracts in diabetic rats. NDC-negative diabetic control, PDC-positive diabetic control, E-ethanol extract. The results of PDC and different aqueous-ethanol extracts were statistically compared with NDC, ${ }^{c} p<0.001$.

\section{Effects of $M$. oleifera fractions in diabetic rats}

Diabetic rats that received the butanol fraction developed significant $(p<0.01)$ acute antihyperglycaemic activity. No other fraction was effective in this regard (Table 5).

\section{Phytochemical profile}

The active butanol fraction and the $95 \%$ (v/v) ethanol extract contained abundant flavonoids, glycosides, tannins, and phenols (Table 6). The aqueous extract lacked alkaloids and terpenoids, whereas hexane fraction contained only tannins and phenols. 


\section{Thin layer chromatogram}

Figure 2 shows three prominent spots in the 95 $\%(v / v)$ ethanol extract and the butanol fraction. These were identified as quercetin 3- $\beta-D$ glucoside, kaempferol 3-O-glucoside, and cryptochlorogenic acid (Figure 3 ), with Rf values of $0.658,0.711$, and 0.316 , respectively.

\section{Identified compounds and validation results}

HPLC chromatograms of the active $95 \%$ (v/v) ethanol extract, the butanol fraction, and the standard mixture are shown in Figure 4. Compound identification was based on the absorption spectra, retention times, and peak

Table 5: Effects of $M$. oleifera fractions in diabetic rats

\begin{tabular}{lcccccc}
\hline Group & Dose & FBG & \multicolumn{3}{c}{ Blood glucose levels after treatment $(\mathbf{m m o l} / \mathbf{L})$} \\
\cline { 5 - 7 }$(\mathbf{n}=6)$ & $\mathbf{p e r ~} \mathbf{k g}$ & $\boldsymbol{O} \boldsymbol{h}$ & $\mathbf{1} \boldsymbol{h}$ & $\mathbf{3} \boldsymbol{h}$ & $\mathbf{5} \boldsymbol{h}$ & $\mathbf{7} \boldsymbol{h}$ \\
\hline NDC & $10 \mathrm{~mL}$ & $20.92 \pm 2.55$ & $21.02 \pm 2.28$ & $20.08 \pm 1.73$ & $19.10 \pm 1.90$ & $20.68 \pm 2.98$ \\
PDC & $500 \mathrm{mg}$ & $18.40 \pm 2.28$ & $15.77 \pm 1.58^{\mathrm{b}}$ & $13.93 \pm 1.96^{\mathrm{c}}$ & $12.85 \pm 1.94^{\mathrm{b}}$ & $10.22 \pm 1.49^{\mathrm{c}}$ \\
HF & $500 \mathrm{mg}$ & $20.92 \pm 1.82$ & $19.83 \pm 1.62$ & $21.15 \pm 0.87$ & $19.83 \pm 1.19$ & $19.98 \pm 1.59$ \\
CF & $500 \mathrm{mg}$ & $18.30 \pm 2.55$ & $21.15 \pm 2.49$ & $20.17 \pm 1.65$ & $19.22 \pm 1.77$ & $18.42 \pm 2.09$ \\
EAF & $500 \mathrm{mg}$ & $18.13 \pm 0.67$ & $19.58 \pm 1.38$ & $18.90 \pm 1.50$ & $19.65 \pm 2.89$ & $18.33 \pm 0.95$ \\
BF & $500 \mathrm{mg}$ & $20.52 \pm 1.23$ & $20.1 \pm 2.31$ & $17.67 \pm 1.93$ & $18.43 \pm 3.48$ & $16.00 \pm 1.27^{\mathrm{b}}$ \\
AF & $500 \mathrm{mg}$ & $19.50 \pm 3.81$ & $20.85 \pm 2.81$ & $19.70 \pm 2.78$ & $18.37 \pm 3.41$ & $18.12 \pm 1.93$ \\
\hline
\end{tabular}

NDC-negative diabetic control, PDC-positive diabetic control, HF-hexane fraction, CF-chloroform fraction, EAF-ethyl acetate fraction, $B F$-butanol fraction, $A F$-aqueous fraction, ${ }^{b}(p<0.01),{ }^{c}(p<0.001)$, Groups were compared with NDC

Table 6: Phytochemical profile of $M$. oleifera extracts and fractions

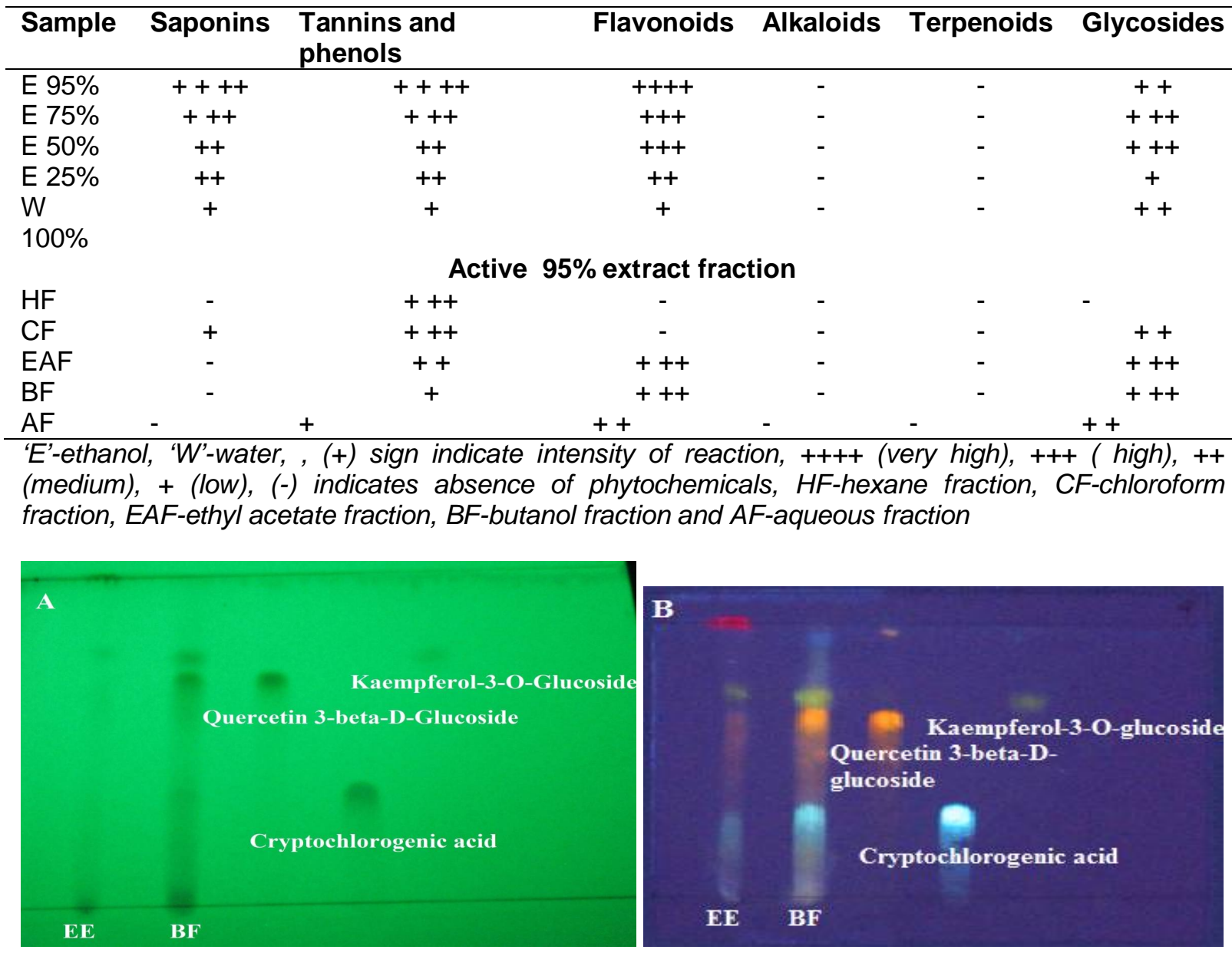

Figure 2: Chromatograms of $M$. oleifera extract, fraction, and identified compounds. EE-ethanol extract, BF-butanol fraction, TLC chromatogram at $254(\mathrm{~A})$ and at $366 \mathrm{~nm}(\mathrm{~B})$. 


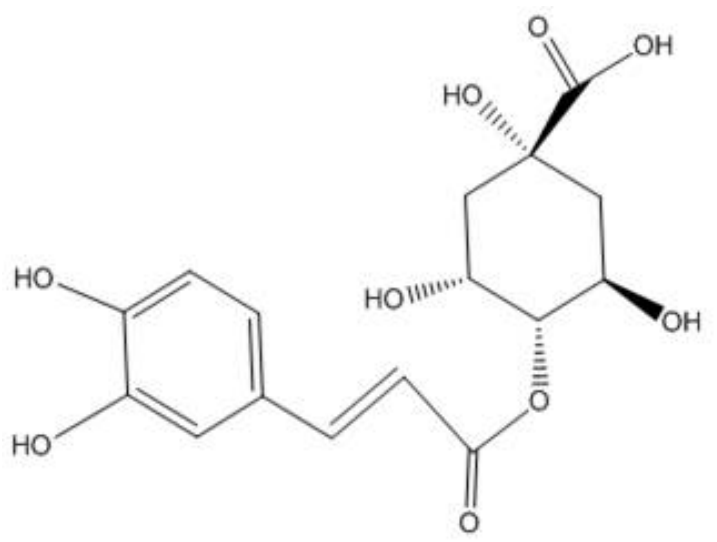

Cryptochlorogenic acid<smiles>O=c1c(O[C@@H]2C[C@H](CO)[C@@H](O)[C@H](O)[C@H]2O)c(-c2ccc(O)cc2)oc2cc(O)cc(O)c12</smiles>

Kaempferol-3-O-glucoside

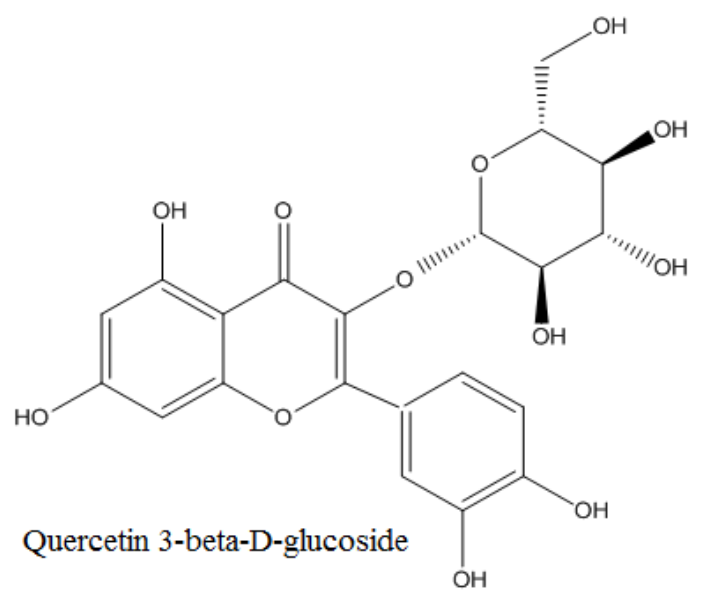

Figure 3: Chemical structures of identified compounds in $M$. oleifera extract and fraction

heights. Kaempferol-3-O-glucoside was present at high levels in the active $95 \%(\mathrm{v} / \mathrm{v})$ ethanol extract and the butanol fraction (56.58 and $216.69 \mu \mathrm{g} / \mathrm{mL}$, respectively). The potential antidiabetic cryptochlorogenic acid content of the butanol fraction was $25.74 \mu \mathrm{g} / \mathrm{mL}$ (Table 7). The limits of detection for cryptochlorogenic acid, quercetin 3- $\beta$-D-glucoside, and kaempferol-3-Oglucoside were $1.515,1.816$ and $1.862 \mu \mathrm{g} / \mathrm{mL}$, respectively. The limits of quantification were $4.590,5.503$, and $5.642 \mu \mathrm{g} / \mathrm{mL}$, respectively (Table 8).

Intra-day accuracy (repeatability) values were from $98.08-100.37 \%$ for cryptochlorogenic acid, $96.07-101.90 \%$ for quercetin 3- $\beta$-D-glucoside, and 95.92 - $101.49 \%$ for Kaempferol-3-Oglucoside. Intra-day precision values were 0.43 $1.72 \%$ for cryptochlorogenic acid, $0.88-1.68 \%$ for quercetin 3- $\beta$-D-glucoside, and $1.27-1.91 \%$ for kaempferol-3-O-glucoside. Inter-day accuracy values were $94.02-101.44 \%$ for cryptochlorogenic acid, 94.11 - $101.72 \%$ for quercetin 3- $\beta$-D-glucoside, and $95.06-101.77 \%$ for kaempferol-3-O-glucoside. Similarly, the interday precision values were $0.44-2.09 \%$ for cryptochlorogenic acid, $1.28-2.05 \%$ for quercetin $3-\beta$-D-glucoside, and $0.55-1.91 \%$ for kaempferol-3-O-glucoside (Table 9).

\section{DISCUSSION}

Anti-diabetic herbal therapies are very important in the field of ethno-pharmacology. Currently, such therapies are urgently needed to replace oral hypoglycaemic drugs, which are increasingly unable to control all pathological symptoms of diabetes, and are often unavailable in remote areas [14]. We evaluated aqueous ethanol extracts of $M$. oleifera in normal and streptozotocin-induced diabetic rats to identify possibly relevant compounds.

The rises in BG levels of normal rats after administration of $M$. oleifera extracts may be attributed to the plant material's content of a high proportion of carbohydrates. Previous studies showed that the $90 \%(\mathrm{v} / \mathrm{v})$ ethanol extract contained $45.43 \%$ carbohydrates [15].

The aqueous-ethanol extracts $(95,75,50,25 \%$ $[\mathrm{v} / \mathrm{v}]$ ethanol and $100 \%$ water) did not exhibit a hypoglycemic effect or affect intraperitoneal GT in normal rats. This lack of effect may be because homeostasis was intact; plant extracts did not interfere with the normal regulation of carbohydrate metabolism [16]. An earlier study [17] also showed no hypoglycaemic effect in normal Wister rats. Data from earlier studies differ somewhat from ours in terms of indications of a hypoglycaemic effect in normal rats; this discrepancy may be attributable to the use of different rat strains, climatic variation in $M$. oleifera species, and/or the doses given. 

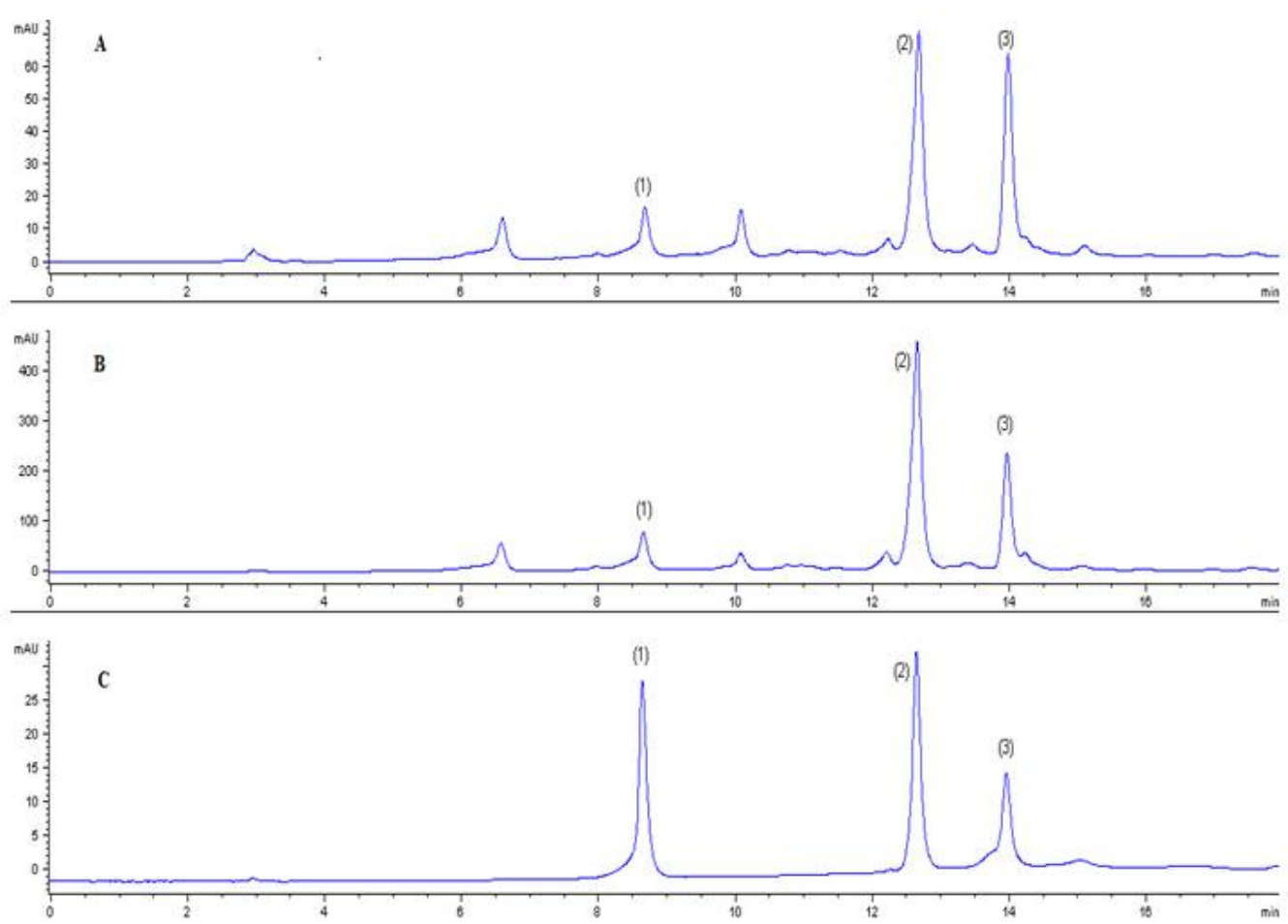

Figure 4: HPLC chromatograms of $M$. oleifera ethanol extract $(A)$, butanol fraction $(B)$ and standard compounds (C), Peaks of cryptochlorogenic acid (1), quercetin 3- $\beta$-D-glucoside (2) and kaempferol-3-O-glucoside (3)

Table 7. Quantification of identified compounds in $M$. oleifera extract and fraction

\begin{tabular}{lccc}
\hline Sample & $\begin{array}{c}\text { Cryptochlorogenic } \\
\text { acid }(\mu \mathrm{g} / \mathbf{m L})\end{array}$ & $\begin{array}{c}\text { Quercetin 3- } \beta-D- \\
\text { glucoside }(\boldsymbol{\mu g} / \mathbf{m L})\end{array}$ & $\begin{array}{c}\text { Kaempferol 3-O- } \\
\text { glucoside }(\boldsymbol{\mu g} / \mathbf{m L})\end{array}$ \\
\hline Active 95\% ethanol extract & 5.16 & 23.90 & 56.58 \\
Active butanol fraction & 25.74 & 159.81 & 216.69 \\
\hline
\end{tabular}

Table 8: Showing linearity, regression values, retention time and LOD_LOQ

\begin{tabular}{|c|c|c|c|c|c|}
\hline Standard & $\begin{array}{l}\text { Linear range } \\
(\mu \mathrm{g} / \mathrm{mL})\end{array}$ & $r^{2}$ & Retention time & $\begin{array}{c}\text { LOD } \\
(\mu \mathrm{g} / \mathrm{mL})\end{array}$ & $\begin{array}{c}\mathrm{LOQ} \\
(\mu \mathrm{g} / \mathrm{mL})\end{array}$ \\
\hline Cryptochlorogenic acid & $12.5-200$ & 0.9991 & 8.64 & 1.515 & 4.590 \\
\hline Quercetin 3- $\beta$-D-glucoside & $12.5-200$ & 0.9999 & 12.64 & 1.816 & 5.503 \\
\hline Kaempferol 3-O-glucoside & $12.5-200$ & 0.9998 & 13.95 & 1.862 & 5.642 \\
\hline
\end{tabular}

Table 9: Inter-day (between day) and intra-day (within day) accuracy and precision of standards (cryptochlorogenic acid, quercetin 3- $\beta$-D-glucoside and kaempferol-3-O-glucoside)

\begin{tabular}{lccccc}
\hline Biological marker & $\begin{array}{c}\text { Concentration } \\
(\boldsymbol{\mu g} / \mathbf{m L})\end{array}$ & \multicolumn{2}{c}{ Inter-day } & \multicolumn{2}{c}{ Intra-day } \\
\cline { 3 - 6 } & & Accuracy $(\%)$ & $\begin{array}{c}\text { Precision } \\
(\%)\end{array}$ & $\begin{array}{c}\text { Accuracy } \\
(\%)\end{array}$ & $\begin{array}{c}\text { Precision } \\
(\%)\end{array}$ \\
\hline Cryptochlorogenic & 12.5 & 94.02 & 1.66 & 98.08 & 0.85 \\
acid & 25 & 99.00 & 2.09 & 99.76 & 1.47 \\
& 50 & 101.44 & 1.61 & 100.37 & 1.72 \\
& 100 & 100.76 & 0.44 & 100.28 & 0.43 \\
Quercetin 3- $\beta$-D- & 200 & 99.76 & 0.15 & 99.92 & 0.78 \\
glucoside & 12.5 & 94.11 & 1.28 & 96.07 & 1.68 \\
& 25 & 99.82 & 1.90 & 97.47 & 1.18 \\
& 50 & 99.65 & 1.60 & 101.90 & 1.47 \\
Kaempferol-3-O- & 100 & 101.72 & 1.41 & 100.60 & 1.63 \\
glucoside & 200 & 99.62 & 2.05 & 99.79 & 0.88 \\
& 12.5 & 95.06 & 1.57 & 98.14 & 1.91 \\
& 25 & 97.58 & 1.61 & 95.92 & 1.27 \\
& 50 & 100.60 & 1.84 & 100.97 & 1.70 \\
\end{tabular}


We found that the $95 \%(\mathrm{v} / \mathrm{v})$ ethanol extract and the butanol fraction thereof were the most active extract and fraction, respectively, exerting very significant acute anti-hyperglycaemic activities in diabetic rats. These effects may be attributable to the expression of glucose transporter-4 (GLUT-4) in the cell membrane, which promotes glucose uptake by skeletal muscle cells and inhibition of glucose synthesis in hepatic cells [18]; skeletal muscle cells constitute $70 \%$ of the total body mass [19]. The results of multiple dosing were in agreement with those of a previous study [20] of the anti-diabetic potential of $M$. oleifera aqueous ethanol extracts $(p<0.001)$. The antihyperglycaemic effect was greater on day 7 than on day 14 , possibly attributable to a reduction in appetite and induction of other anti-diabetic mechanisms.

Initially, we tested various isocratic and gradient systems in terms of optimum separation of compounds using a mobile phase $(0.1 \%[\mathrm{v} / \mathrm{v}]$ formic acid and acetonitrile). The isocratic method did not adequately separate phenolic compounds; only the gradient method produced well-resolved sharp peaks that absorbed at 344 $\mathrm{nm}$.

Linearity was evident over the range of 12.5 $200 \mu \mathrm{g} / \mathrm{mL}$ for cryptochlorogenic acid, quercetin 3- $\beta$-D-glucoside, and kaempferol-3-O-glucoside $\left[r^{2}=0.9991(y=3.1452 x+3.0369), r^{2}=0.9999\right.$ $(y=3.1485 x-1.8511)$, and $r^{2}=0.9998(y=$ $1.1045 x+0.0278)$ respectively; time vs. peak height in mAU]. The data shown in Table 9 confirm the validity of the HPLC method in terms of intra-day and inter-day precision, accuracy, and repeatability. TLC also identified isoquercetin, astragalin, and crypto-chlorogenic acid in the $70 \%[\mathrm{v} / \mathrm{v}]$ ethanol extract of $M$. oleifera leaves [21].

\section{CONCLUSION}

The anti-hyperglycaemic effect of the $M$. oleifera $95 \%(\mathrm{v} / \mathrm{v})$ ethanol extract and the butanol fraction thereof in diabetic rats may be attributable to cryptochlorogenic acid, quercetin $3-\beta-D-g l u c o s i d e$, and kaempferol-3-O-glucoside. This extract, and the compounds mentioned, may be alternative treatments for diabetes, and may prompt further drug discovery.

\section{ACKNOWLEDGEMENT}

We would like to acknowledge Mohammad Razak, Science Officer of the Centre for Drug Research, Universiti Sains Malaysia, for assisting with the HPLC analysis. We thank the University of Sargodha, Sargodha, Pakistan, for a faculty development scholarship to Hafiz Muhammad Irfan. The work was supported by a grant from Ministry of Education, Malaysia (no. 203/PFARMASI/6711451).

\section{DECLARATIONS}

\section{Conflict of Interest}

No conflict of interest associated with this work.

\section{Contribution of Authors}

The authors declare that this work was done by the authors named in this article and all liabilities pertaining to claims relating to the content of this article will be borne by them.

\section{Open Access}

This is an Open Access article that uses a funding model which does not charge readers or their institutions for access and distributed under the terms of the Creative Commons Attribution License (http://creativecommons.org/licenses/by 14.0) and the Budapest Open Access Initiative (http://www.budapestopenaccessinitiative.org/rea d), which permit unrestricted use, distribution, and reproduction in any medium, provided the original work is properly credited.

\section{REFERENCES}

1. Saltiel AR. Diverse signaling pathways in the cellular actions of insulin. Am J Physiol 1996; 270: E375-E385.

2. Gonz' alez C, Beruto V, Keller G, Santoro S, Di Girolamo G. Investigational treatments for Type 2 diabetes mellitus: exenatide and liraglutide, Expert Opinion on Investigational Drugs 2006; 15: 887-895.

3. International Diabetes Federation Atlas. 6th edition. http://www.idf.org/diabetesatlas/downloaded in 30/11/2013.

4. Wan Nazaimoon WM, Md Isa SH, Wan Mohamad WB, Khir AS, Kamaruddin NA, Kamarul IM, Mustafa N, Ismail IS, Ali O, Khalid BAK. Prevalence of diabetes in Malaysia and usefulness of $\mathrm{HbA1C}$ as a diagnostic criterion. Diabet Med 2013; 30: 825-828.

5. Pan SY, Zhou SF, Gao SH, Yu ZL, Zhang SF, Tang MK, Sun JN, Ma DL, Han YF, Fong, WF et al. New perspectives on how to discover drugs from herbal medicines: CAM's outstanding contribution to modern therapeutics. Evid Based Complement Alternat Med 2013; Article ID 627375, 25.

6. Kadir AA. Biodiversity prospecting of tropical plants for medicinal uses. Third National Congress on Genetics. Forest Research Institute Malaysia (FRIM) Kapong Selangor, Malaysia. 1998; 149-151. 
7. Littleton J, Rogers T, Falcone D. Novel approaches to plant drug discovery based on high throughput pharmacological screening and genetic manipulation. Life Sci 2005; 78: 467-475.

8. Kushwaha SK, Kushwaha N, Maurya N, Rai AK. Role of markers in the standardization of herbal drugs: A review. Arch Appl Sci Res 2010; 2: 225- 229.

9. Sasidharan S, Chen $Y$, Saravanan D, Sundram KM, Latha LY. Extraction, Isolation and Characterization of Bioactive Compounds from Plants' Extracts. Afr J Tradit Complement Altern Med 2011; 8: 1-10.

10. Rasheed NM, Nagaiah K, Goud PR, Sharma VU. Chemical marker compounds and their essential role in quality control of herbal medicine. Ann Phytomed 2012, 1: 1-8.

11. Guide for the Care and Use of Laboratory Animals. Committee for the Update of the Guide for the Care and Use of Laboratory Animals. 8th edition. The National Academies Press. Washington, (DC), US; 2011. Available from: https://grants.nih.gov/grants/olaw/Guidefor--the-care-and-use-of-laboratory-animals.pdf.

12. Harborne JB. Phytochemical methods-A guide to modern techniques of plant analysis 3rd edition. New Delhi: Springer Pvt. Ltd; 2005.

13. Trease GE, Evans WE. Pharmacognosy, 11th edn; Bailliere Tindall, London; 1989: 45-50.

14. Marles RJ, Farnsworth NR. Antidiabetic plants and their active constituents. Phytomedicine 1995; 2: 137-189.

15. Oluduro OA, Idowu TO, Aderiye BI, Famurewa $O$, Omoboye OO. Evaluation of antibacterial potential of crude extract of Moringa oleifera seed on orthopaedics wound isolates and characterization of phenylmethanamine and benzyl isothiocyanate derivatives. Research journal of medicinal plants 2012; 6: 383-394.

16. Vats V, Grover JK, Rathi SS. Evaluation of antihyperglycemic effect of Trigonella foenum-graecum Linn, Ocimum sanctum Linn and Pterocarpus marsupium Linn, in normal and alloxanised diabetic rats. J Ethnopharmacol 2002; 79: 95-100.

17. Tende JA, Ezekiel I, Dikko AAU, Goji ADT. Effect of ethanolic leaves extract of Moringa oleifera on blood glucose levels of streptozocin-induced diabetics and normoglycemic Wistar rats. Brit J Pharmacol Toxicol 2011; 2: 1-4.

18. Guillén A, Granados S, Rivas KE, Estrada O, Echeverri $L F$, Balcázar N. Antihyperglycemic activity of Eucalyptus tereticornis in insulin-resistant cells and a nutritional model of diabetic mice. Adv Pharmacol Sci 2015; Article ID 418673, 10.

19. Abdul-Ghani MA, DeFronzo RA. "Pathogenesis of insulin resistance in skeletal muscle," J Biomed and Biotechnol 2010; Article ID 476279, 19. doi: 10.1155/2010/476279.

20. Irfan HM, Asmawi MZ, Nurzalina AKH. A review on promising phytochemical, nutritional and glycemic control studies on Moringa oleifera Lam. in tropical and sub-tropical regions. Asian Pac J Trop Biomed 2016; 6: 930-936. Doi:10.1016/j.apjtb.2016.08.006.

21. Vongsak $B$, Sithisarn $P$, Gritsanapan W. Simultaneous determination of crypto-chlorogenic acid, isoquercetin, and astragalin contents in Moringa oleifera leaf extracts by TLC-densitometric method. Evid Based Complement Alternat Med 2013; Article ID 917609, 7. 